Article

\title{
Upscaling Inverted Perovskite Solar Cells: Optimization of Laser Scribing for Highly Efficient Mini-Modules
}

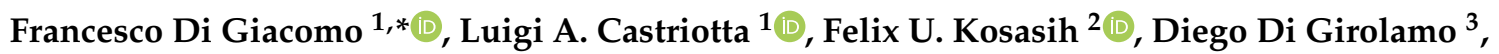 \\ Caterina Ducati ${ }^{2}$ and Aldo Di Carlo $1,4, * \mathbb{D}$ \\ 1 Centre for Hybrid and Organic Solar Energy (CHOSE), Department of Electronic Engineering, \\ University of Rome Tor Vergata, 00133 Rome, Italy; luigi.angelo.castriotta@uniroma2.it \\ 2 Department of Materials Science and Metallurgy, University of Cambridge, 27 Charles Babbage Road, \\ Cambridge CB3 0FS, UK; fuk21@cam.ac.uk (F.U.K.); cd251@cam.ac.uk (C.D.) \\ 3 Department of Chemical Materials and Production Engineering, University if Naples Federico II, \\ Piazzale Tecchio 80, Fuorigrotta, 80125 Naples, Italy; diego.digirolamo91@gmail.com \\ 4 LASE-Laboratory for Advanced Solar Energy, National University of Science and Technology MISiS, \\ Leninsky Ave. 6, 119049 Moscow, Russia \\ * Correspondence: francesco.di.giacomo@uniroma2.it (F.D.G.); aldo.dicarlo@uniroma2.it (A.D.C.)
}

Received: 16 November 2020; Accepted: 16 December 2020; Published: 20 December 2020

\begin{abstract}
The upscaling of perovskite solar cells is one of the challenges that must be addressed to pave the way toward the commercial development of this technology. As for other thin-film photovoltaic technologies, upscaling requires the fabrication of modules composed of series-connected cells. In this work we demonstrate for the first time the interconnection of inverted modules with $\mathrm{NiO}_{\mathrm{x}}$ using a UV ns laser, obtaining a $10.2 \mathrm{~cm}^{2}$ minimodule with a $15.9 \%$ efficiency on the active area, the highest for a $\mathrm{NiO}_{x}$ based perovskite module. We use optical microscopy, energy-dispersive X-ray spectroscopy, and transfer length measurement to optimize the interconnection. The results are implemented in a complete electrical simulation of the cell-to-module losses to evaluate the experimental results and to provide an outlook on further development of single junction and multijunction perovskite modules.
\end{abstract}

Keywords: perovskite solar cells; laser ablation; perovskite solar module

\section{Introduction}

The research on perovskite photovoltaics gained great momentum in the past 10 years. Major improvements in the efficiency and stability of perovskite solar cells (PSCs) have been achieved, making this technology the most efficient and promising in the class of thin-film photovoltaics (PV). Record small area devices have achieved certified power conversion efficiencies (PCEs) of 25.5\% lately [1]. The versatility of PSCs is reflected by the variety of architectures that have been reported. We can identify two main classes: n-i-p and p-i-n cells. The former starts with an electron transport layer (ETL) over the transparent conductive oxide (TCO) and so far has been exhibiting relatively higher PCEs [2]. The p-i-n stack (also called inverted) reverses the order of the layers: it starts with a hole transport layer (HTL) on top of the TCO, followed by the perovskite layer, an electron transport layer (ETL), and a top electrode. It is often reported to be more stable and can be made without expensive HTL or top electrode materials (e.g., spiro-OMeTAD or Au often used in n-i-p PSCs) [3]. These advantages make it a more viable candidate for the development of commercial products, but the research on large-area perovskite devices is still mostly focused on the n-i-p architecture. Recently, the development of large-area $\mathrm{p}-\mathrm{i}-\mathrm{n}$ devices has been accelerated by the successful implementation of 
polytriarylamine (PTAA) as an HTL [4-6], while there are only a few reports on large-area inverted PSCs using a $\mathrm{NiO}_{x}$ HTL [7-9].

Besides the deposition of the layers over large areas, the upscaling of thin-film PV requires the development of monolithic interconnection to fabricate series-connected modules (if one excludes the use of Si/thin-film tandem). The need for the series interconnection arises from a series of arguments. The layers required for any thin-film PV technologies, i.e., cadmium telluride (CdTe), copper indium gallium sulfide/selenide (CIGS/Se), microcrystalline silicon ( $\mu \mathrm{c}-\mathrm{Si}$ ) or amorphous silicon (a-Si), as well as organic PV and perovskite PV, can be deposited on large-sized substrates (i.e., in the $\mathrm{m}^{2}$ range). This advantage eliminates the additional costs and area losses required by the series connection of Si wafers used in crystalline silicon PV. At least one of the electrodes of a PV device (excluding interdigitated back-contact cells, an uncommon choice for thin-film PV) is based on a TCO to allow the collection of the incident light [10]: this layer cannot be too thick to maintain a good degree of transparency, consequently limiting the sheet resistance to values in the order of 7 to $60 \Omega \square^{-1}$ [11]. While the resistivity of the TCO could be negligible for small area devices $\left(<1 \mathrm{~cm}^{2}\right)$, this is not the case for large area ones. There are two options to mitigate the resistive losses: either the use of a current-collecting metal grid as for Si wafers or to divide the module into multiple series-connected cells. A metal grid is well-suited for Si wafers but will not be sufficient for devices in the scale of square meters (a $2 \mathrm{~m}^{2}$ module with $25 \mathrm{~mA} \mathrm{~cm}{ }^{-2}$ current density output would generate $500 \mathrm{~A}$ of current). Since the layers of a thin-film device are deposited over a substrate (glass sheet, polymer foil, or metal foil), they can be patterned during their deposition (i.e., by shadow masks for vacuum deposition or by printing techniques for solution processing) or afterwards (by laser ablation or mechanical scribing). Using one of these methods, it is possible to pattern the layers to fabricate a module composed of series-connected cells. In this arrangement, the module's output current is limited to that of one subcell, drastically decreasing the resistive losses and removing the need for current-collecting grids. This method is the most frequently used to upscale a thin-film solar cell and PSCs are no exception $[12,13]$. The voltage of the module will be, ideally, the sum of the subcells voltages, while the current of the module will be limited by the lowest current produced by any of the subcells. Therefore, developing a homogeneous deposition process for the functionals layers is essential to maximize the module performance.

The most common method employed to realize the interconnection of such an architecture is called P1-P2-P3 process. The P1 process insulates the bottom electrode of neighboring cells. The P2 patterning step selectively removes a slice of the entire layer stack, except TCO, between adjacent cells to permit their series connection through subsequent deposition of the top electrode. Finally, the P3 step is applied to separate the just-realized top electrode layer. An interconnection scheme (Figure 1, top left) is constituted by some active zones that are dedicated to the photogeneration of electric charges and, thus, to the photovoltaic energy conversion, and dead zones, dedicated to the interconnection between adjacent cells. It is possible to define the Active Area (AA) as that part of the substrate dedicated to the photovoltaic energy conversion and the Dead Area (DA), as the part where the interconnection of cells takes place, and which does not contribute to the energy conversion. The DA is formed by the P1, P2 and P3 zones and by two safety areas that are interposed between them. The ratio between the photoactive area (AA) and the aperture area of the module (AR, the sum of active and dead area) is usually referred to as the geometric fill factor (GFF).

The most common architecture used for perovskite modules is the n-i-p structure. It was used for the first modules fabricated back in 2014 with a PCE of $6.3 \%$ on $16.8 \mathrm{~cm}^{2}$ [14], and after years of research, it allowed the fabrication of a $21 \mathrm{~cm}^{2}$ module with a PCE of $18.13 \%$ in 2020 [15]. The upscaling of p-i-n cells can be more challenging due to the thin transport layers used, but a lot of progress has been made in recent years by using PTAA as an HTL. A record PCE of 19.1\% (on AA, 17\% on AR) was recently obtained using a combination of blade coating and thermal evaporation [6]. Compared to PTAA, there are only a few reports on inverted perovskite modules based on $\mathrm{NiO}_{x}$. We believe that $\mathrm{NiO}_{\mathrm{x}}$ is a strong candidate for $\mathrm{p}-\mathrm{i}-\mathrm{n}$ modules due to its high stability [3], low cost, and lack of wetting 
issues which are often reported for organic HTLs such as PTAA [16]. There are also a variety of deposition techniques that can be used on large areas, ranging from spray coating to sputtering [17]. Liao et al. reported the first $\mathrm{NiO}_{x}$-based modules in 2017. They used a sol-gel ink to deposit the $\mathrm{NiO}_{x}$ layer on $5 \times 5 \mathrm{~cm}^{2}$ substrates and used mechanical scribing with a blade for the P2 contact, obtaining an active area PCE of 12\% [7]. During the same year Troughton et al. developed a process to implement the antisolvent deposition in air, fabricating modules with a PCE of $11.8 \%$ using mechanical scribing for the $\mathrm{P} 2$ contact [9]. Also the last report on $\mathrm{NiO}_{\mathrm{x}}$-based modules made use of mechanical scribing, showing the lack of literature on the laser interconnection of this kind of module [8]. In this other work, Abzieher et al. developed the electron beam evaporation of $\mathrm{NiO}_{\mathrm{x}}$ for highly efficient PSCs. Using thermal evaporation for the perovskite layer, as well as for the ETLs and the top contact, they obtained an all-evaporated minimodule of $2.3 \mathrm{~cm}^{2}$ area with a PCE of $12.4 \%$. While mechanical scribing is also used in the industrial production of thin-film modules and it has been implemented in the fabrication of several perovskite modules [7-9,18], it has several disadvantages compared to laser ablation such as a large scribe width, chipping, and incompatibility with flexible substrates $[19,20]$. The evaluation of the P2 scribing process requires the understanding of the quality of the ablation: a qualitative evaluation can be achieved with a combination of optical microscopy and energy-dispersive X-ray spectroscopy (EDX) (see Figures 2 and 3) [18]. On the other hand, the quantification of resistive losses expected in a P2 contact can be used to predict the impact on the module efficiency. This necessitates a transfer length measurement (TLM) in combination with electrical simulations. TLM allows the quantification of the contact resistance and introduces the concept of transfer length $\left(\mathrm{L}_{T}\right)$ [21]. With this measurement we can properly simulate the losses in the P2 scribe. The cell-to-module losses can be separated into three contributions [22-25]: the resistive loss due to the electrode (in particular the TCO), the resistive loss in the P2 contact, and the area loss due to the interconnection. Besides, we should consider that the increase in the active area makes the modules more sensitive to defects, especially since in a series connection the total current at a given voltage is limited by the lowest among the different cells. The contribution of defects is not considered in the simulation, and it is evaluated by estimating the difference between the simulated module efficiency and the actual efficiency.

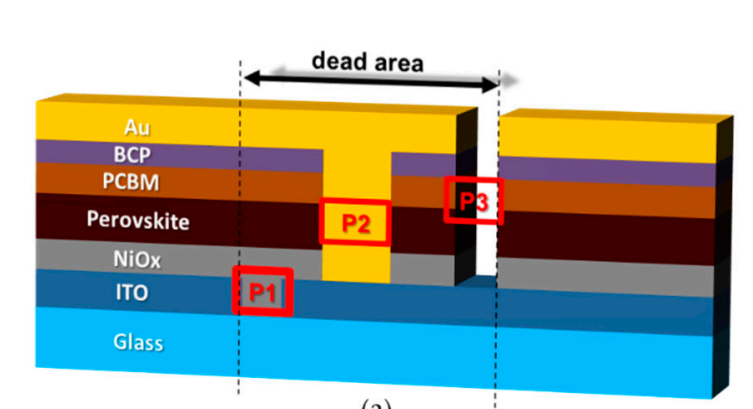

(a)

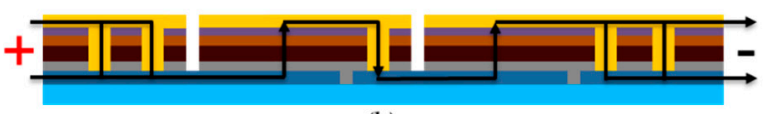

(b)

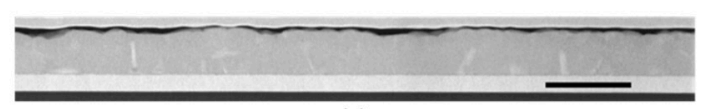

(c)

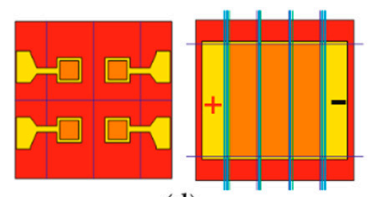

(d)

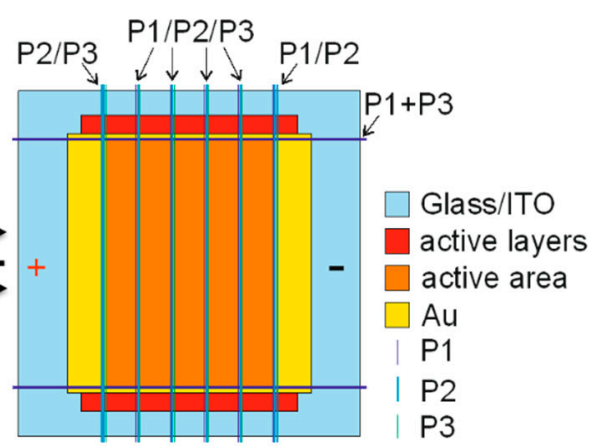

(e)

Figure 1. (a) A scheme of the pin architecture used and of the P1 P2 P3 interconnection; (b) A scheme of the charge flow in the series connection among cells and toward the contact; (c) Cross-sectional STEM-HAADF image of the stack used (scale bar is $1 \mu \mathrm{m}$ ); (d) design of the $0.09 \mathrm{~cm}^{2}$ cell and of the $2.25 \mathrm{~cm}^{2}$ modules; (e) Design of the $10.2 \mathrm{~cm}^{2}$ module.

In this work, we compared electrical stimulation and experimental results to evaluate the shift from small cells to modules, with a particular focus on the laser interconnection. We demonstrated 
for the first time the use of UV laser ablation for $\mathrm{NiO}_{\mathrm{x}}$-based modules and we estimated the resistive losses that arise from the size of the electrodes and the series interconnection as well as the geometric losses induced by the area dedicated to the interconnection. This enables a quantification of the total expected losses from those factors so that any additional losses can be addressed to defects generated during the fabrication procedure. We also provide an outlook that describes the possible evolution of perovskite modules and the best-case scenarios that we foresee.

\section{Materials and Methods}

Dimethylformamide (DMF-anhydrous-Sigma Aldrich), dimethyl sulfide (DMSO-anhydrous-Sigma Aldrich), 2-methoxyethanol (2-ME-anhydrous-Sigma Aldrich), chlorobenzene (CB-anhydrous-Sigma Aldrich), dichlorobenzene (DCB-anhydrous-Sigma Aldrich), Nitric acid (70\%-Sigma Aldrich), isopropanol (IPA-anhydrous-Sigma Aldrich), Nickel chloride hexahydrate ( $\mathrm{NiCl} \cdot 6 \mathrm{H}_{2} \mathrm{O}-99.9 \%-S i g m a$ Aldrich), [6,6]-phenyl-C 61 -butyric acid methyl ester (PCBM-99\%-Solenne), Bathocuproine (BCP-96\%-Sigma Aldrich), methylammonium bromide (MABr-99.99\%-Greatcell solar), formamidinium iodide (FAI-99.99\%-Greatcell solar), Cesium iodide (CsI-99.99\%-Sigma Aldrich), Lead Bromide ( $\left.\mathrm{PbBr}_{2}-\mathrm{TCI}\right)$, Lead Iodide ( $\left.\mathrm{PbI}_{2}-\mathrm{TCI}\right)$, 1-butyl-3-methylimidazolium tetrafluoroborate (BMITFB-98\%-ACROS) were purchased and used without further purification. Glass/ITO substrates $\left(10 \Omega \square^{-1}\right)$ were purchased from Kintec.

The nickel oxide ink was prepared by adding $35.5 \mathrm{mg}$ of $\mathrm{NiCl} \cdot 6 \mathrm{H}_{2} \mathrm{O}$ to $1 \mathrm{~mL}$ of 2-ME. After adding $20 \mu \mathrm{L}$ of nitric acid the solution was heated at $75^{\circ} \mathrm{C}$ for two hours [26]. The ink was aged for at least 2 days before use. The perovskite triple cation ink $\left(\mathrm{Cs}_{0.05} \mathrm{MA}_{0.1425} \mathrm{FA}_{0.8075} \mathrm{PbI}_{2.7} \mathrm{Br}_{0.3}\right)$ was prepared by adding $1521.8 \mathrm{mg}$ of $\mathrm{PbI}_{2}, 104.3 \mathrm{mg}$ of $\mathrm{PbBr}_{2}, 44.8 \mathrm{mg}$ of $\mathrm{CsI}, 479.1 \mathrm{mg}$ of FAI and $55.0 \mathrm{mg}$ of MABr to $1.899 \mathrm{~mL}$ of DMF and $0.601 \mathrm{~mL}$ of DMSO. The formulation contains a $4 \%$ excess of lead salts, and a DMF: DMSO volume ratio of 3.16:1. $50 \mu \mathrm{L}$ of BMITFB were added to $1 \mathrm{~mL}$ of DMF [3], and $20 \mu \mathrm{L}$ of this solution was added to $1 \mathrm{~mL}$ of the perovskite ink. Electron transport layers (ETLs) solution were prepared by adding $27 \mathrm{mg}$ of PCBM to $750 \mu \mathrm{L}$ of CB and $250 \mu \mathrm{L}$ of DCB, and by adding $5 \mathrm{mg}$ of BCP to $10 \mathrm{~mL}$ of IPA.

\subsection{Cell Fabrication}

$2.5 \times 2.5 \mathrm{~cm}^{2}$ glass/ITO samples were patterned with a UV ns laser (Spectraphysics - Andover, MA, USA) and diced with a glasscutter (Dyenamo - Stockholm, Sweden). Samples were scrubbed with water and soap solution (Hellmanex $2 \%$ in deionized water) and cleaned with three stages of ultrasonic bath: first in water and soap, then in ultrapure water, and finally in IPA. After drying they were treated for $15 \mathrm{~min}$ in a $\mathrm{UV} / \mathrm{O}_{3}$ tool (Novasonic). The nickel oxide ink was spun at $4000 \mathrm{RPM}$ for $30 \mathrm{~s}$ and annealed for $5 \mathrm{~min}$ at $75^{\circ} \mathrm{C}, 10 \mathrm{~min}$ at $120^{\circ} \mathrm{C}$ and one hour at $300^{\circ} \mathrm{C}$. After cooling down, the samples were transferred in a nitrogen-filled glovebox. The perovskite ink was spun at 4000 RPM for $35 \mathrm{~s}$, and $180 \mu \mathrm{L}$ of $\mathrm{CB}$ were dropped after $20 \mathrm{~s}$. The film was annealed for $10 \mathrm{~min}$ at $100{ }^{\circ} \mathrm{C}$. PCBM was spun at $1700 \mathrm{RPM}$ for $30 \mathrm{~s}$ and annealed at $100{ }^{\circ} \mathrm{C}$ for $5 \mathrm{~min}$. BCP was spun at $4000 \mathrm{RPM}$. $100 \mathrm{~nm}$ of gold were deposited by thermal evaporation, using a shadow mask to separate the four cells that are fabricated on each substrate.

\subsection{Module Fabrication}

$5.6 \times 5.6 \mathrm{~cm}^{2}$ glass/ITO samples were patterned and cleaned like small cells, and the same procedure was used to deposit all the layers (increasing the volume of ink and antisolvents used for spin coating of a factor of 3.5). The interconnection was made via a P1-P2-P3 scheme as shown in Figure 1. The optimal fluence per pulse (amount of energy of a single laser pulse divided for the area of the laser spot) was $280 \mathrm{~mJ} \mathrm{~cm}^{-1}$ for P1, $118 \mathrm{~mJ} \mathrm{~cm}^{-1}$ for the P2, and $90 \mathrm{~mJ} \mathrm{~cm}^{-1}$ for the P3. All the ablations were carried out from the top side of the device at a repetition rate of $80 \mathrm{kHz}$, with a scanning speed of $195 \mathrm{~mm} \mathrm{~s}^{-1}$. The patterns of the different scribes are shown in Figure 1. The P2 scribes were made after the deposition of all the layers up to the BCP, while the P3 scribes were made after the evaporation of the Au electrode. The samples for TLM followed the same procedures of the module, 
but the design is different (see Figure 4). No P3 was needed for TLM samples. The P2 ablation is made of a set of parallel scribes with an RSD (raster scan distance) of $10 \mu \mathrm{m}$. The P3 ablation is made of a set of parallel scribes with an RSD of $15 \mu \mathrm{m}$. The width of P1 is the one of a single scribe, in this case $15 \mu \mathrm{m}$. The width of P2 range from 60 to $300 \mu \mathrm{m}$ (see last section of the results), while the width of P3 scribes is $105 \mu \mathrm{m}$. The cell width was equal to $5 \mathrm{~mm}$ and the interconnection width was fixed to $500 \mu \mathrm{m}$, and the P2 was centered between P1 and P3 scribes. For this reason, the distance among P2 and P2 or P2 and P3 was $40 \mu \mathrm{m}$ for a P2 of $300 \mu \mathrm{m}, 90 \mu \mathrm{m}$ for a P2 of $200 \mu \mathrm{m}$, and $160 \mu \mathrm{m}$ for a P2 of $60 \mu \mathrm{m}$.

\subsection{Characterization}

Cell and module were measured with an ABET Sun 2000 class A sun simulator, calibrated with an Eko MS-602 pyranometer. The accuracy of the calibration was checked by measuring the internal quantum efficiency of cells (Arkeo system from Cicci Research, Grosseto, Italy), ensuring that the mismatch of the integrated and measured JSC was less than 4\%. Data were acquired with a 4-channels source meter unit of Cicci Research with a scan rate of $100 \mathrm{mV} \mathrm{s}^{-1}$ for cells, $300 \mathrm{mV} \mathrm{s}^{-1}$ for modules with three cells, and $500 \mathrm{mV} \mathrm{s}^{-1}$ for modules with five cells. Resistance measurement of TLM samples was performed with a Keithley 2420 in 4-wire mode, using round copper probes. The absorbance of the $\mathrm{NiO}_{x}$ film was measured on glass microslides using a UV-Vis 2550 Spectrophotometer from Shimadzu (Kyoto, Japan).

Scanning electron microscopy (SEM) images and EDX elemental maps were acquired using a FEI Nova NanoSEM (ThermoFisher formerly FEI, Eindhoven, The Netherlands) fitted with a Bruker XFlash 6 EDX detector (Bruker Nano, Berlin, Germany). EDX maps and spectra were processed using Esprit 1.9 software. The current and voltage settings are $27 \mathrm{pA}, 2 \mathrm{kV}$ for imaging and $200 \mathrm{pA}, 10 \mathrm{kV}$ for EDX mapping. For cross-sectional TEM imaging, a lamella was prepared using a FEI Helios Nanolab Dualbeam FIB/SEM following a standard procedure [27]. This lamella was then immediately transferred into a FEI Osiris TEM operated in scanning mode (STEM) at $200 \mathrm{kV}$. The high-angle annular dark field (HAADF) image was acquired using a Fischione detector (Fischione, Hanau, Germany) with a dwell time of $1 \mu \mathrm{s} /$ pixel.

\section{Results}

A first step to initiate an upscaling activity is the selection of a stack that can provide efficient and reproducible results. In this work we focused on a $\mathrm{p}-\mathrm{i}-\mathrm{n}$ architecture made of glass/ITO/NiO $/ \mathrm{Cs}_{0.05} \mathrm{MA}_{0.1425} \mathrm{FA}_{0.8075} \mathrm{PbI}_{2.7} \mathrm{Br}_{0.3}+\mathrm{BMITFB} / \mathrm{PCBM} / \mathrm{BCP} / \mathrm{Au}$ (see Figure 1). The type of TCO and the addition of BMITFB ionic liquid were selected after a preliminary comparison (see Figure S1). The ionic liquid should also reduce the ion migration within the perovskite to prevent its degradation $[3,28]$. This type of PSCs showed PCEs between 16 and 17\% with a low spread in the results, easing the fabrication of balanced modules. Since a module is made by a set of series-connected cells, the module's current will be limited by the cell with the lowest current. Furthermore, due to the larger area and more complex fabrication, the modules often come with a lower set of samples produced. The strategy selected for the series connection is the fabrication of a P1-P2-P3 interconnection by performing three laser ablation processes with a ns UV laser. The P1-P2-P3 scheme is shown in Figure 1.

In this work, we fabricated three types of PV devices: small PSCs with four $0.09 \mathrm{~cm}^{2}$ active areas on $2.5 \times 2.5 \mathrm{~cm}^{2}$ substrates, 3-cell minimodules with an active area of $2.25 \mathrm{~cm}^{2}$ on $2.5 \times 2.5 \mathrm{~cm}^{2}$ substrates, and 5-cell minimodules with an active area of $10.2 \mathrm{~cm}^{2}$ on $5.6 \times 5.6 \mathrm{~cm}^{2}$ substrates (see Figure 1). The smaller minimodules were used to optimize the fabrication of the interconnection since they can be fabricated in larger numbers (improving the statistical relevance of the results) and do not require changes in the layer deposition protocol when compared to small cells. Besides the selection of the stack and proper design of the module, to enable the fabrication of modules it is necessary to develop the laser scribing processes. P1 and P3 scribes are used to electrically separate the electrodes of adjacent cells. The P1 scribing of glass/TCO samples is usually the simplest one and does not 
require specific investigation. A single laser line with a width of $15 \mu \mathrm{m}$ was sufficient to provide insulation among different areas of the ITO (Figure S2). The P3 scribe is more challenging since the layers underneath the top metal electrode may be damaged by parasitic heating induced by the laser pulses [29]. Nevertheless, it was possible to successfully transfer the P3 process for gold electrodes as developed in previous studies, obtaining good electrical insulation with a P3 width ranging from 90 to $150 \mu \mathrm{m}$ [30]. The main focus in the development of an efficient interconnection was on the optimization of the P2 scribe. The P2 should remove all the layers from the bottom transport layer (here $\mathrm{NiO}_{\mathrm{x}}$ ) up to the top transport layer (here BCP) without damaging the bottom electrode. The UV wavelength used $(355 \mathrm{~nm})$ is absorbed by all the layers of the stack, including ITO. This requires careful tuning of the laser fluence to optimize the trade-off between incomplete removal of the layers at low fluences and ITO damage at high fluences. In particular, the laser is only partially absorbed by the $\mathrm{NiO}_{\mathrm{x}}$ layer (see Figure S3), suggesting that it might be challenging to achieve a selective removal of all the $\mathrm{NiO}_{x}$ without arming the ITO. An optical image of a power scan is reported in Figure 2.

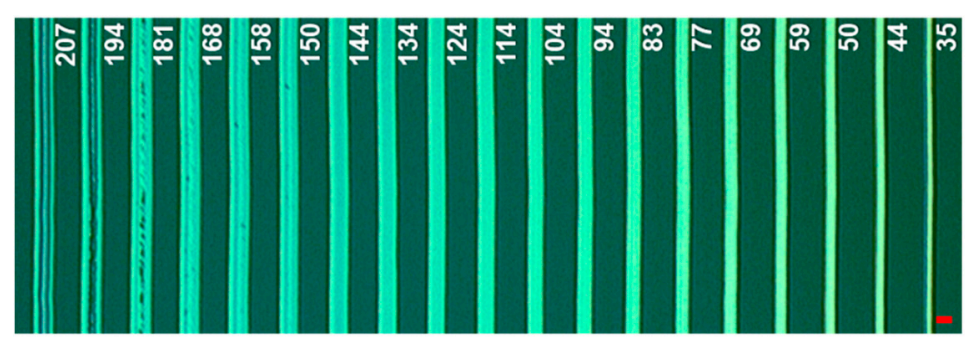

(a)

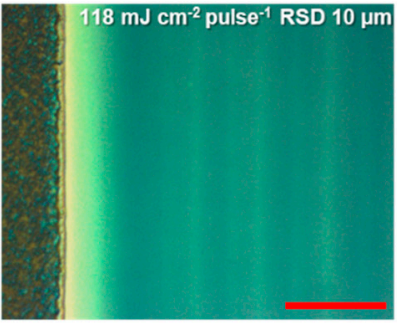

(c)

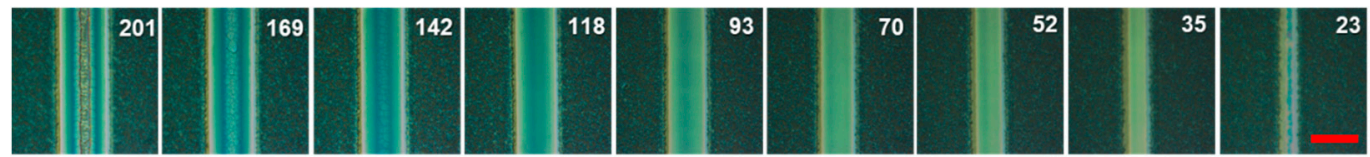

(b)

Figure 2. (a) Optical microscope image of a P2 power scan with a 355 UV ns laser over a sample made of glass/ITO/NiO $/$ perovskite/PCBM/BCP. The numbers indicate the fluence per pulse in $\mathrm{mJ} \mathrm{cm}^{-2}$. Given the scribing speed of $195 \mathrm{~mm} \mathrm{~s}^{-1}$ and a pulse frequency of $80 \mathrm{kHz}, 12$ pulses overlap in each point; (b) Microscope image of P2 scribes at different fluence per pulse; (c) The image of the P2 ablation used for modules, in which a series of P2 scribes are done parallel to each other with a distance (RSD) of $10 \mu \mathrm{m}$. The red scale bars indicate $30 \mu \mathrm{m}$.

At low fluences per pulse (amount of energy of a single laser pulse divided for the area of the laser spot, $<70 \mathrm{~mJ} \mathrm{~cm}^{-2}$ pulse ${ }^{-1}$ ) we can observe a narrow ablation line. In these cases, the fluence is above the ablation threshold only at the center of the laser beam: the power density of the laser beam typically has a Gaussian shape and, in these images, we can only observe the width of the ablated material. The yellow color of the reflected light also suggests the incomplete removal of the layers. This is supported by the yellow color observed at the side of each P2 scribe even at higher fluences: at the side of each scribe the ablation is incomplete due to the Gaussian shape of the intensity of the laser spot. At high fluences, we can observe the cracking of the ITO layer (fluence $>130 \mathrm{~mJ} \mathrm{~cm}^{-2}$ pulse $^{-1}$ ) or its complete ablation in the center of the scribe (fluence $>190 \mathrm{~mJ} \mathrm{~cm}^{-2}$ pulse $^{-1}$ ). The optimal fluence lies in between these two boundaries (poor ablation and ITO cracking). Furthermore, to provide a sufficient width of the P2 contact, we used a set of parallel scribes at a raster scanning distance (RSD) of $10 \mu \mathrm{m}$ (see top right panel of Figure 2). A P2 scribe with a fluence of $118 \mathrm{~mJ} \mathrm{~cm} \mathrm{~cm}^{-2}$ pulse $^{-1}$ and an RSD of $10 \mu \mathrm{m}$ was selected for in-depth characterization. It is important to underline that the optimization of the P2 scribe with optical microscopy (i.e., by observing the color of the different areas of the scribe) is eased by the low roughness of the ITO electrode that gives rise to interference contrast, enabling the detection of thin transparent layers by observing the color of the image. We believe that a similar analysis would be more challenging for a rougher TCO such as fluorine-doped tin oxide. 
Figure 3 shows the top-view EDX analysis of the P2 scribe and the area surrounding it. The perovskite-forming elements $(\mathrm{C}, \mathrm{Pb}, \mathrm{I}$, and $\mathrm{Br})$ are removed from the $\mathrm{P} 2$ scribe with excellent selectivity without removing the ITO layer. However, the removal of $\mathrm{NiO}_{\mathrm{x}}$ is incomplete as indicated by the small nickel peak at $0.85 \mathrm{keV}$ in the P2 Line spectrum. Ideally, the $\mathrm{NiO}_{\mathrm{x}}$ layer should be entirely removed to minimize series resistance. However, due to the $\mathrm{NiO}_{\mathrm{x}}$ layer's low thickness (about $15 \mathrm{~nm}$ ) and the lack of selectivity of the UV laser, it is very challenging to remove it completely without damaging the ITO layer. We note that although the EDX spectra and the nickel map in Figure 3 seem to indicate that there is the same amount of nickel both inside and outside the P2 line, this is actually not the case. There is far less nickel inside the P2 line as outside P2, approximately 91\% of the generated $\mathrm{Ni}$-L $\alpha$ X-ray photons were absorbed by the perovskite layer and hence did not reach the EDX detector (see Figure S4). On the other hand, $\mathrm{NiO}_{\mathrm{x}}$ is the topmost layer inside the P2 line so effectively all the $\mathrm{Ni}-\mathrm{L} \alpha \mathrm{X}$-ray photons generated there were able to escape from the sample surface.

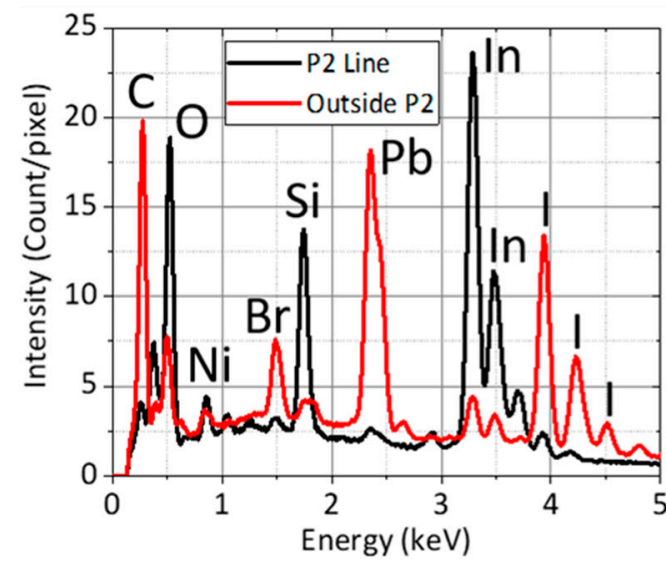

(a)

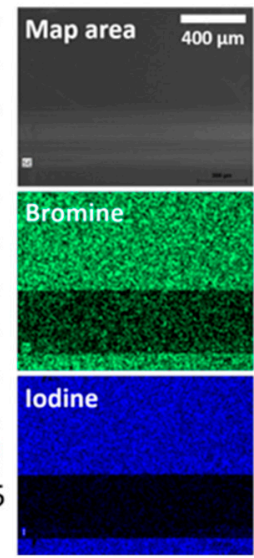

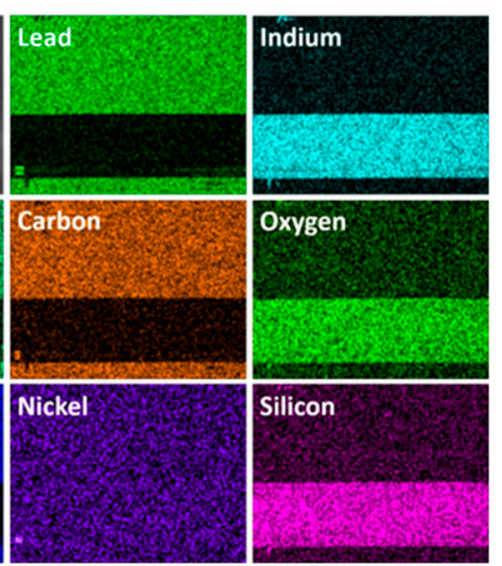

(b)

Figure 3. (a) Average EDX spectra over the P2 line and the area outside it; (b) A matrix of SEM image and EDX elemental maps. The P2 is located on the bottom side of each map.

To understand the impact of the incomplete removal of $\mathrm{NiO}_{x}$, we performed a TLM analysis of the contacts. In this way, we can quantify the quality of the P2, and we can use the results to simulate the resistive losses that can be expected. The TLM is required to have a proper estimation of the resistive losses since the high aspect ratio of a thin-film contact (width of the contact over the thickness of layers) prevents a more direct measurement [21].

The geometry of this kind of contact (metal over a less conductive thin semiconductor) is characterized by a high aspect ratio among the width of the contact and the thickness of the electrode, inducing current crowding on one side of the contact: the current flowing on one edge of the contact is high, and its density decays in an exponential fashion with a characteristic length $\mathrm{L}_{\mathrm{T}}$. In other words, the effective contact length can be much smaller than the actual contact length, and there is no need to exceed $\mathrm{L}_{\mathrm{T}}$ when defining the optimal width of a P2 contact. For this reason, $\mathrm{L}_{\mathrm{T}}$ is a more significant parameter than the contact resistance to calculate the efficiency of a P2 contact, and it is needed to perform a proper electrical simulation of a module. We can consider $\mathrm{L}_{\mathrm{T}}$ as the length that the charges travel in the TCO before they are transferred to the contact. It is related to both specific contact resistance $\left(\rho_{\mathrm{C}}\right)$ and the conductivity of the electrode $\left(\mathrm{R}_{\mathrm{SH}}\right)$ with the following equation:

$$
\mathrm{L}_{\mathrm{T}}=\sqrt{\frac{\rho_{\mathrm{C}}}{\mathrm{R}_{\mathrm{SH}}}} .
$$


With this definition, we can express the total resistance $\left(\mathrm{R}_{\mathrm{T}}\right)$ measured with TLM as:

$$
\mathrm{R}_{\mathrm{T}}=\frac{\mathrm{R}_{\mathrm{SH}}}{\mathrm{W}}\left(\mathrm{L}+\mathrm{L}_{\mathrm{T}}\right),
$$

where $\mathrm{W}$ is the width (perpendicular to the current flow) of the contact and $\mathrm{L}$ is the distance between contacts. A summary of the TLM results is shown in Figure 4.

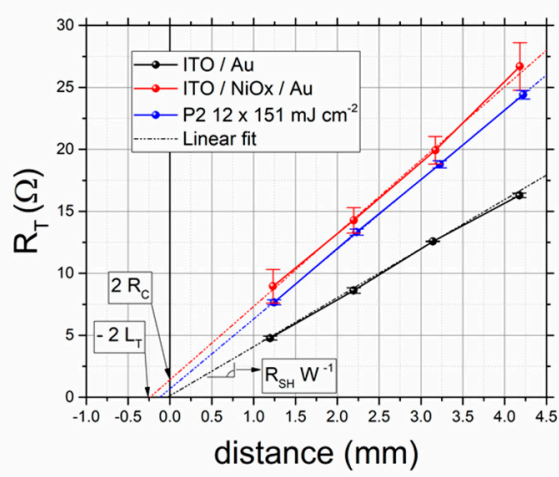

(a)

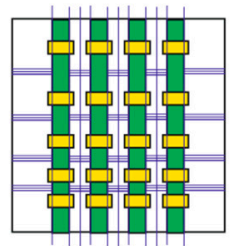

(b)

\begin{tabular}{cccc}
\hline & $R_{S H}\left(\Omega \square^{-1}\right)$ & $\rho_{C}\left(\Omega \mathrm{cm}^{2}\right)$ & $\mathrm{L}_{T}(\mathrm{~cm})$ \\
ITO Au & $9.9 \pm 0.3$ & $0.0003 \pm 0.0007$ & $0.002 \pm 0.004$ \\
ITO NiOx Au & $14.8 \pm 0.5$ & $0.021 \pm 0.009$ & $0.012 \pm 0.005$ \\
\hline P2 12x 118 mJ cm-2 & $14.06 \pm 0.09$ & $0.0053 \pm 0.0007$ & $0.0061 \pm 0.0009$ \\
\hline
\end{tabular}

(c)

Figure 4. (a) Transfer length measurement (TLM) plot with an indication of the important parameters measure; (b) Design of the samples used for TLM: purple lines represent P1 scribes, yellow pads represent the gold contact and green pads indicate the four stripes used for TLM; (c) Summary table with the parameters measured in the TLM analysis.

As expected, the lowest transfer length is obtained with an ITO/Au contact without any interlayer and the results obtained are in line with the ones already presented in the literature [24]. Interestingly, the sheet resistance of the TCO increase from 10 to about $15 \Omega \square^{-1}$ after the deposition and annealing of the $\mathrm{NiO}_{\mathrm{x}}$. 4-point probe measurement reveals that the sheet resistance does not increase by heating the bare ITO to $300{ }^{\circ} \mathrm{C}$, so the increase in resistivity is due to the deposition of $\mathrm{NiO}_{\mathrm{x}}$. We speculate that the acidity of the sol-gel or the migration of $I n$ to the $\mathrm{NiO}_{x}$ can be the reasons behind this phenomenon. The presence of $\mathrm{NiO}_{\mathrm{x}}$ in between ITO and Au increases the transfer length from 0.002 to $0.012 \mathrm{~cm}$ (increase in $\rho_{\mathrm{c}}$ from 0.0003 to $0.02 \Omega \mathrm{cm}^{2}$ ). While this is a considerable increase, the impact on the cell-to-module losses is almost negligible if one uses a P2 width of more than $100 \mu \mathrm{m}$ (see next section). The $\mathrm{L}_{\mathrm{T}}$ measured for the solar cell stack after the laser ablation discussed above (shown in Figure 2) is considerably lower, thanks to the reduction of $\rho_{C}$. This measurement confirms that the laser ablation process can partially remove the $\mathrm{NiO}_{x}$ layer. The remaining $\mathrm{NiO}_{x}$ (as also observed in the EDX) justify the higher contact resistance compared to a direct ITO/Au contact. To understand if the proposed P2 ablation process is sufficient to minimize the cell-to-module losses it is necessary to break down the loss factors. We implemented a model developed for thin film-modules (and already used for perovskite PV) that separate the losses into three factors [22-25]: the geometrical losses due to the dead area of the P1-P2-P3 interconnection $\left(\mathrm{f}_{\mathrm{G}}\right)$, the resistive losses due to the $\mathrm{TCO}\left(\mathrm{f}_{\mathrm{TCO}}\right)$, and the resistive losses due to the $\mathrm{P} 2$ contact $\left(\mathrm{f}_{\mathrm{P} 2}\right)$. These are calculated using the following equations:

$$
\begin{gathered}
\mathrm{f}_{\mathrm{G}}=\frac{\mathrm{w}_{\text {int. }}}{\mathrm{w}_{\text {int. }}+\mathrm{w}_{\text {active }}}, \\
\mathrm{f}_{\mathrm{TCO}}=\frac{\mathrm{J}_{\mathrm{MPP}}}{\mathrm{V}_{\mathrm{MPP}}} \cdot \frac{\mathrm{R}_{\mathrm{SH}}^{\mathrm{TCO}}}{3} \cdot \frac{\mathrm{w}_{\text {active }}^{3}}{\mathrm{w}_{\text {active }}+\mathrm{w}_{\text {int. }}}, \\
\mathrm{f}_{\mathrm{P} 2}=\frac{\mathrm{J}_{\mathrm{MPP}}}{\mathrm{V}_{\mathrm{MPP}}} \cdot \frac{\mathrm{w}_{\text {active }}^{2}}{\mathrm{w}_{\text {active }}+\mathrm{w}_{\text {int. }}} \cdot \mathrm{L}_{\mathrm{T}} \mathrm{R}_{\mathrm{SH}}^{\mathrm{P} 2} \operatorname{coth} \frac{\mathrm{w}_{\mathrm{P} 2}}{\mathrm{~L}_{\mathrm{T}}},
\end{gathered}
$$


where $w_{\text {int }}$ is the width of the interconnection (from P1 to P3 of the same interconnection), $w_{\text {active }}$ is the active width of the cell (from one P3 to the P1 of the next interconnection), $\mathrm{w}_{\mathrm{P} 2}$ is the width of the P2 scribe, $\mathrm{R}_{\mathrm{SH}}$ is the sheet resistance (in the TCO or the P2), $\mathrm{J}_{\mathrm{MPP}}$ is the maximum power point current density and $\mathrm{V}_{\text {MPP }}$ is the maximum power point voltage. The trends of the different functions are plotted in Figure 5.

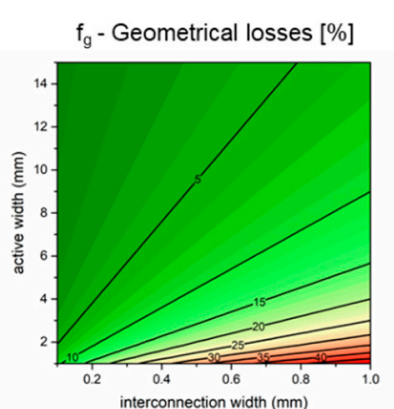

(a)

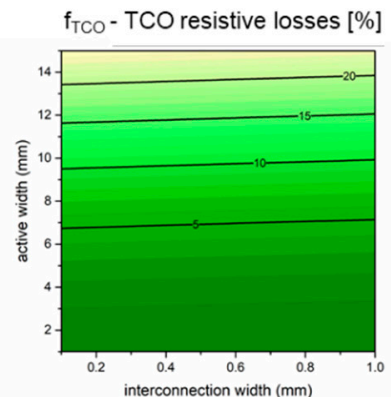

(b)

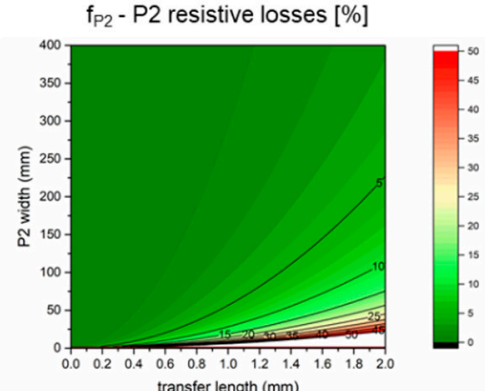

(c)

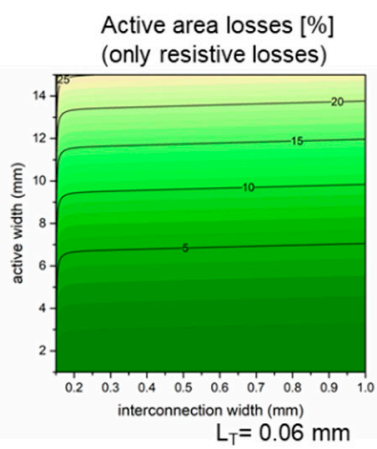

(d)

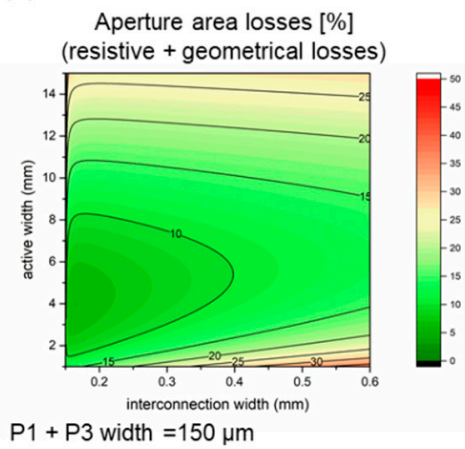

(e)

Figure 5. Breakdown of the relative cell-to-module efficiency losses. (a) Geometrical losses due to the presence of the interconnection; (b) The resistive losses due to the TCO; (c) The resistive losses due to the P2 contact; (d) The losses expected on active area efficiency; (e) The losses expected on aperture area efficiency. The TCO considered here has a $\mathrm{R}_{\mathrm{SH}}$ of $15 \Omega \square^{-1}, \mathrm{~J}_{\mathrm{MPP}}$ is $19 \mathrm{~mA} \mathrm{~cm}{ }^{-2}$ and $\mathrm{V}_{\mathrm{MPP}}$ is $850 \mathrm{mV}$.

If we focus on the losses due to the P2 scribe, we can observe that with a $\mathrm{L}_{\mathrm{T}}$ of $0.06 \mathrm{~mm}$ any $\mathrm{w}_{\mathrm{P} 2}$ above $10 \mu \mathrm{m}$ will result in resistive losses lower than $0.1 \%$, meaning that the P2 ablation developed is well-suited to make inverted modules with high efficiency. Even without removing the $\mathrm{NiO}_{x}$ $\left(\mathrm{L}_{\mathrm{T}}=0.2 \mathrm{~mm}\right)$, it is possible to have rather low losses, i.e., a loss of $0.2 \%$ with a $\mathrm{w}_{\mathrm{P} 2}$ of $10 \mu \mathrm{m}$ or a loss of $0.1 \%$ with a $\mathrm{w}_{\mathrm{P} 2}$ of $120 \mu \mathrm{m}$. The other losses are affected by the resistivity of the TCO and the design of the module (i.e., $\mathrm{w}_{\text {active }}$ and $\mathrm{w}_{\text {int. }}$ ). If one wants to maximize the active area efficiency of the module, only the resistive losses will matter $\left(\mathrm{f}_{\mathrm{TCO}}\right.$ and $\mathrm{f}_{\mathrm{P} 2}$ ), while the geometrical losses should be considered only in the aperture area efficiency. To understand the expected losses on the module, we fixed the $\mathrm{L}_{\mathrm{T}}$ to the one obtained with our laser ablation, and we calculated the interconnection width as wP2 plus $150 \mu \mathrm{m}$ for the P1 and P3. To maximize the active area efficiency, it is important to minimize $\mathrm{w}_{\text {active }}$ to reduce the resistive losses in the TCO, while the impact of the interconnection is negligible whenever the P2 is wider than $15 \mu \mathrm{m}$. This is true only if the $\mathrm{L}_{\mathrm{T}}$ of the P2 contact is low enough to prevent large losses in the P2 contact, otherwise $\mathrm{w}_{\mathrm{P} 2}$ would have a larger impact also on the active area PCE [22]. Given $\mathrm{L}_{\mathrm{T}}$ obtained with our P2 ablation, we do not expect any difference in modules with $\mathrm{w}_{\mathrm{P} 2}$ ranging from 60 to $300 \mu \mathrm{m}$. To have experimental confirmation of this calculation we fabricated minimodules with three cells connected in series for a total active area of $2.25 \mathrm{~cm}^{2}$. In Figure 6 we can observe that there is a negligible difference among minimodules with P2 of 300 or $60 \mu \mathrm{m}$ in width. 


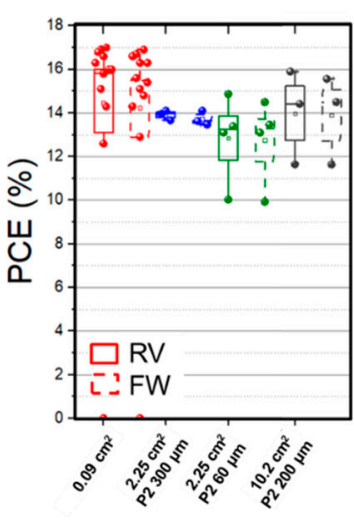

(a)

\begin{tabular}{ccccc}
\hline Active area & $\mathbf{V}_{\mathrm{OC}}$ & $\mathrm{J}_{\mathrm{SC}}$ & $\mathrm{FF}$ & PCE \\
\hline $\mathrm{cm}^{2}$ & $\mathrm{~V}$ & $\mathrm{~mA} \mathrm{~cm}{ }^{-2}$ & $\%$ & $\%$ \\
0.09 & 1.00 & 21.5 & 79.4 & 17.0 \\
2.25 & 3.13 & 20.0 & 73.8 & 15.4 \\
10.2 & 5.27 & 22.0 & 68.4 & 15.9 \\
\hline
\end{tabular}

(b)

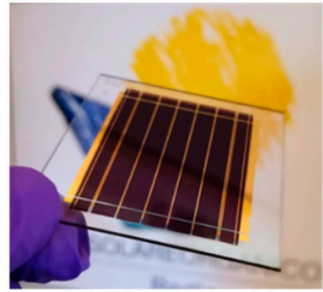

(c)

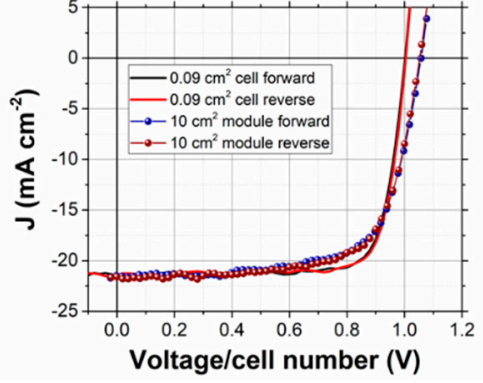

(d)

Figure 6. (a) Box plot of the active area efficiencies of the devices fabricated for this work; (b) Summary table with the PV parameter of the best device per each size; (c) Picture of the $10.2 \mathrm{~cm}^{2}$ module; (d) JV curve (voltage is divided by number of cells) of the best 0.09 and $10.2 \mathrm{~cm}^{2}$ device.

The larger spread when using $\mathrm{w}_{\mathrm{P} 2}$ of $60 \mu \mathrm{m}$ can be due to local disconformity in the layers that lead to a longer $\mathrm{L}_{\mathrm{T}}$ or to extrinsic factors. This suggests that widening the P2 could lead to a more robust process without any negative impact on the active area PCE. Furthermore, the $2.25 \mathrm{~cm}^{2}$ modules have a JSC lower than the cell, most likely due to an unbalance among cells. We speculate that the antisolvent washing used for the perovskite layer is not uniform in the center of the sample, and this issue can have a noticeable impact due to the small size of the cells. When $10.2 \mathrm{~cm}^{2}$ modules were fabricated the $\mathrm{J}_{\mathrm{SC}}$ was in line with one of the small cells. By increasing the $\mathrm{w}_{\mathrm{P} 2}$ to $120 \mu \mathrm{m}$ we aimed to mitigate any issue related to disuniformity in the P2 ablation process. Given the larger area of the devices and the lower number of samples, it is crucial to take all the precautions to increase the yield of the process. In this way, we demonstrated the fabrication of inverted modules with $\mathrm{NiO}_{\mathrm{x}}$ with an active area efficiency of $15.9 \%$ (14.5\% on aperture area, with a geometrical fill factor of $90.9 \%)$, the highest for a $\mathrm{NiO}_{\mathrm{x}}$-based perovskite module (calibration verified via IPCE of a small cell, see Figure S5). If we consider that the $\mathrm{w}_{\text {active }}$ is $5 \mathrm{~mm}$ and the $\mathrm{w}_{\text {int. }}$ is $500 \mu \mathrm{m}$, we would expect a cell-to-module loss of $3 \%$. It is worth noticing that for a fairer comparison, we should exclude the resistive losses included in the measurement of the small cell, as well as the loss in $\mathrm{V}_{\mathrm{OC}}$ due to the use of illumination masks (see Figure S6) [31]. Even if the lack of mask would likely induce the reduction of FF, this reduction should not be considered to evaluate the cell-to-module losses since it is specific for a given cell layout [32]. If we include these corrections, we should increase the PCE of the small cells of a factor of $4 \%$, leading to modules with potential active area efficiency of $17.2 \%$. The additional losses (7.5\% relative) may be attributed to the increase of defects that are often related to any upscaling activity. Indeed, if we consider the average efficiency of the small cells $(16.5 \%$ after the corrections mentioned above), the potential active area efficiency of the module would be $16 \%$. This confirms that the losses observed are in line with reasonable expectations and that improving the reproducibility of the process is a key requirement for any improvement in the upscaling activities. The last plot of Figure 5 shows the expected losses on the aperture area, which is important to define the energy yield of a PV module. There we can observe how critical the miniaturization of the P2 scribe is and the need for a low $\mathrm{L}_{\mathrm{T}}$, since the cell-to-module losses can be lower than $6 \%$ only with a cell width of $4 \mathrm{~mm}$ and an interconnection width of $166 \mu \mathrm{m}$. We can observe the impact of $\mathrm{L}_{\mathrm{T}}$ on the aperture area PCE with the simulation presented in Figure S7: increasing $\mathrm{L}_{\mathrm{T}}$ to $0.2 \mathrm{~mm}$ limit the minimum loss to $7.5 \%$ due to the widening of $\mathrm{w}_{\mathrm{P} 2}$ that increase the geometrical losses. Besides improving the laser ablation process (i.e., reducing safety areas or the width of P1 and P3), a significant reduction of the losses can be achieved only by lowering the $\mathrm{R}_{\mathrm{SH}}$ of the TCO or by minimizing the $\mathrm{J}_{\mathrm{MMP}}$ to $\mathrm{V}_{\mathrm{MPP}}$ ratio (see Equation (4) and (5)). For the former, we can simulate the aperture area PCE losses when using a 
TCO with $7 \Omega \square^{-1}$, a value that can be easily obtained by using fluorine-doped tin oxide. With this type of TCO we can lower the minimum aperture area PCE loss to $4.6 \%$ thanks to a decrease in the resistive loss in the electrode that allows for wider cells. This might not result in an improvement of the overall efficiency due to the reduced transparency of more conductive TCO. Reducing $R_{S H}$ below $7 \Omega \square^{-1}$ requires the addition of collecting grids: in this case, the improvement in $R_{S H}$ must be balanced with the absorption losses due to the shadowing of the grid. We believe that the improvement introduced by grids for series-connected modules would be minor, while they will be essential for large area cells (i.e., for the front contact of a Si/perovskite tandem). Once both $\mathrm{L}_{\mathrm{T}}$ and $\mathrm{R}_{\mathrm{SH}}$ are minimized the only factor that can be tuned is the $\mathrm{J}_{\mathrm{MMP}}$ to $\mathrm{V}_{\mathrm{MPP}}$ ratio. The ratio used in our simulation would not change significantly even considering highly efficient single-junction PSCs, since they would increase both $\mathrm{J}_{\mathrm{MMP}}$ and $\mathrm{V}_{\mathrm{MPP}}$. To achieve a significant lowering of these parameters we must consider the use of two-junction or three-junction tandems [33]. All-perovskite tandems are an interesting approach to go beyond the efficiency limit for a single junction PSC and using them for perovskite modules would simultaneously lower the $\mathrm{J}_{\text {MPP }}$ and increase the $\mathrm{V}_{\text {MPP. }}$. When we simulate the cell-to-module losses for a two-junction tandem cell with PCE of $27 \%$ and a three-junction tandem cell with PCE of $30.8 \%$ ( $\mathrm{J}_{\mathrm{MPP}}$ and $\mathrm{V}_{\mathrm{MPP}}$ used are reported in the table of Figure S7) we can observe that the expected losses decrease to $3.3 \%$ and $2.6 \%$ respectively (corresponding to modules with aperture area PCE of $26.1 \%$ and $30 \%$ ). The results indicate how the increase of PCE obtained with tandem structures compared to single junction PSC will be amplified during the upscaling from cell to modules.

\section{Conclusions}

In conclusion, we demonstrated that is possible to obtain an efficient P2 ablation of inverted PSCs with $\mathrm{NiO}_{x}$ using a ns UV laser. This is the first published report of a UV laser ablation process for a $\mathrm{NiO}_{\mathrm{x}}$-based module. A large part of the optimization was carried out with optical microscopy, while SEM-EDX showed that the removal of $\mathrm{NiO}_{\mathrm{x}}$ is incomplete. The P2 contact was also studied by a TLM analysis to quantify the quality of the contact by measuring the transfer length $\mathrm{L}_{\mathrm{T}}$. By knowing this factor, we simulated the cell-to-module losses to better evaluate the results obtained during the upscaling study. The validity of the estimation of the resistive losses was also verified experimentally by varying the width of $\mathrm{P} 2$ in $2.25 \mathrm{~cm}^{2}$ modules, confirming the prediction of the simulations. With the optimized P2, we were able to fabricate a $10.2 \mathrm{~cm}^{2}$ module with an active area PCE of $15.9 \%$, only $6.5 \%$ lower than the best results on small cells. This represents the highest efficiency for a perovskite module using $\mathrm{NiO}_{\mathrm{x}}$ as the HTL. Since the expected losses on active area were equal to $3 \%$, the efficiency of the module is in line with the average PCE of small cells. To further improve this structure, it is required to increase the reproducibility of the processes (improving the fabrication protocol or by using a stack that is less sensitive to defects) and improve the overall PCE of the cells. From the theoretical analysis of the losses, we can suggest that further reduction in the cell-to-module losses on aperture area can be achieved by minimizing the width of the interconnection, by lowering the sheet resistance of the TCO and by moving to a tandem structure, where the losses can be as low as $2.6 \%$ for a three-junction device.

Supplementary Materials: The following are available online at http://www.mdpi.com/2072-666X/11/12/1127/s1, Figure S1: box plots of the PV parameters of pin solar cells with different TCOs and with or without the addition of BMITFB. Figure S2: picture of a P1 P2 P3 interconnection. Figure S3: absorbance spectra of the $\mathrm{NiO}_{\mathrm{x}}$ layer. Figure S4: simulation of the absorbed and emitted EDX photons of the $\mathrm{NiO}_{\mathrm{x}}$. Figure S5: IPCE measurement of the stack used for module fabrication. Figure S6: effect of mas on the JV measurement of small cells. Figure S7: Additional simulation of cell-to-module losses.

Author Contributions: F.D.G. and A.D.C. conceived the work. F.D.G. developed the cell architecture, the design and fabrication protocol of the modules, and carried out the TLM and theoretical studies. L.A.C. carried out the laser ablation of the modules and optimized the laser ablation for P1, P2, and P3. F.U.K. performed the SEM-EDX and TEM characterization. D.D.G. developed the recipe of $\mathrm{NiO}_{x}$ and performed UV-vis measurement. C.D. supervised F.U.K. and coordinated the activities on electron microscopy. A.D.C. supervised F.D.G. and L.A.C. and coordinated the activities on device fabrication and electrical simulation. All authors have read and agreed to the published version of the manuscript. 
Funding: F.D.G. thanks the ESPResSo project (Horizon 2020, grant 764047) for funding. L.A.C gratefully acknowledges the European Union's Horizon 2020 Framework Program for funding Research and Innovation under grant agreement no. 764787 (MAESTRO). F.U.K. thanks the Jardine Foundation and Cambridge Trust for a doctoral scholarship. A.D.C. gratefully acknowledges the financial support from the Ministry of Education and Science of the Russian Federation in the framework of MegaGrant (no. 075-15-2019-872 (14.Y26.31.0027/074-02-2018-327)).

Conflicts of Interest: The authors declare no conflict of interest.

\section{References}

1. Green, M.A.; Dunlop, E.D.; Hohl-Ebinger, J.; Yoshita, M.; Kopidakis, N.; Ho-Baillie, A.W.Y. Solar cell efficiency tables (Version 55). Prog. Photovolt. Res. Appl. 2020, 28, 3-15. [CrossRef]

2. Yoo, J.J.; Wieghold, S.; Sponseller, M.C.; Chua, M.R.; Bertram, S.N.; Hartono, N.T.P.; Tresback, J.S.; Hansen, E.C.; Correa-Baena, J.P.; Bulović, V.; et al. An interface stabilized perovskite solar cell with high stabilized efficiency and low voltage loss. Energy Environ. Sci. 2019, 12, 2192-2199. [CrossRef]

3. Bai, S.; Da, P.; Li, C.; Wang, Z.; Yuan, Z.; Fu, F.; Kawecki, M.; Liu, X.; Sakai, N.; Wang, J.T.W.; et al. Planar perovskite solar cells with long-term stability using ionic liquid additives. Nature 2019, 571, 245-250. [CrossRef] [PubMed]

4. Subbiah, A.S.; Isikgor, F.H.; Howells, C.T.; De Bastiani, M.; Liu, J.; Aydin, E.; Furlan, F.; Allen, T.G.; Xu, F.; Zhumagali, S.; et al. High-Performance Perovskite Single-Junction and Textured Perovskite/Silicon Tandem Solar Cells via Slot-Die Coating. ACS Energy Lett. 2020, 5, 3034-3040. [CrossRef]

5. Deng, Y.; van Brackle, C.H.; Dai, X.; Zhao, J.; Chen, B.; Huang, J. Tailoring solvent coordination for high-speed, room-temperature blading of perovskite photovoltaic films. Sci. Adv. 2019, 5, eaax7537. [CrossRef]

6. Deng, Y.; Ni, Z.; Palmstrom, A.F.; Zhao, J.; Xu, S.; Van Brackle, C.H.; Xiao, X.; Zhu, K.; Huang, J. Reduced Self-Doping of Perovskites Induced by Short Annealing for Efficient Solar Modules. Joule 2020, 4, 1949-1960. [CrossRef]

7. Liao, H.C.; Guo, P.; Hsu, C.P.; Lin, M.; Wang, B.; Zeng, L.; Huang, W.; Soe, C.M.M.; Su, W.F.; Bedzyk, M.J.; et al. Enhanced Efficiency of Hot-Cast Large-Area Planar Perovskite Solar Cells/Modules Having Controlled Chloride Incorporation. Adv. Energy Mater. 2017, 7, 1-9. [CrossRef]

8. Abzieher, T.; Moghadamzadeh, S.; Schackmar, F.; Eggers, H.; Sutterlüti, F.; Farooq, A.; Kojda, D.; Habicht, K.; Schmager, R.; Mertens, A.; et al. Electron-Beam-Evaporated Nickel Oxide Hole Transport Layers for Perovskite-Based Photovoltaics. Adv. Energy Mater. 2019, 9, 1-13. [CrossRef]

9. Troughton, J.; Hooper, K.; Watson, T.M. Humidity resistant fabrication of $\mathrm{CH} 3 \mathrm{NH} 3 \mathrm{PbI} 3$ perovskite solar cells and modules. Nano Energy 2017, 39, 60-68. [CrossRef]

10. Ginley, D.S.; Bright, C. Transparent Conducting Oxides. MRS Bull. 2000, 25, 15-18. [CrossRef]

11. Galagan, Y.; Coenen, E.W.C.; Verhees, W.J.H.; Andriessen, R. Towards the scaling up of perovskite solar cells and modules. J. Mater. Chem. A 2016, 4, 5700-5705. [CrossRef]

12. Yaghoobi Nia, N.; Lamanna, E.; Zendehdel, M.; Palma, A.L.; Zurlo, F.; Castriotta, L.A.; Di Carlo, A. Doping Strategy for Efficient and Stable Triple Cation Hybrid Perovskite Solar Cells and Module Based on Poly(3-hexylthiophene) Hole Transport Layer. Small 2019, 15, 1904399. [CrossRef] [PubMed]

13. Park, N.-G.; Zhu, K. Scalable fabrication and coating methods for perovskite solar cells and solar modules. Nat. Rev. Mater. 2020, 5, 333-350. [CrossRef]

14. Matteocci, F.; Razza, S.; Di Giacomo, F.; Casaluci, S.; Mincuzzi, G.; Brown, T.M.; D’Epifanio, A.; Licoccia, S.; Di Carlo, A. Solid-state solar modules based on mesoscopic organometal halide perovskite: A route towards the up-scaling process. Phys. Chem. Chem. Phys. 2014, 16, 3918-3923. [CrossRef]

15. Li, J.; Wang, H.; Chin, X.Y.; Dewi, H.A.; Vergeer, K.; Goh, T.W.; Lim, J.W.M.; Lew, J.H.; Loh, K.P.; Soci, C.; et al. Highly Efficient Thermally Co-evaporated Perovskite Solar Cells and Mini-modules. Joule 2020, 4, 1035-1053. [CrossRef]

16. Schultes, M.; Giesbrecht, N.; Küffner, J.; Ahlswede, E.; Docampo, P.; Bein, T.; Powalla, M. Universal Nanoparticle Wetting Agent for Upscaling Perovskite Solar Cells. ACS Appl. Mater. Interfaces 2019, 11, 12948-12957. [CrossRef]

17. Di Girolamo, D.; Di Giacomo, F.; Matteocci, F.; Marrani, A.G.; Dini, D.; Abate, A. Progress, highlights and perspectives on $\mathrm{NiO}$ in perovskite photovoltaics. Chem. Sci. 2020, 11, 7746-7759. [CrossRef]

18. Meroni, S.M.P.; Hooper, K.E.A.; Dunlop, T.; Baker, J.A.; Worsley, D.; Charbonneau, C.; Watson, T.M. Scribing Method for Carbon Perovskite Solar Modules. Energies 2020, 13, 1589. [CrossRef] 
19. Kato, T. Recent Research Progress of High-Efficiency CIGS Solar Cell in Solar Frontier 23. In Proceedings of the IW-CIGSTech: 32th EU PVSEC, Munich, Germany, 20-24 June 2016.

20. Gečys, P.; Markauskas, E.; Nishiwaki, S.; Buecheler, S.; De Loor, R.; Burn, A.; Romano, V.; Račiukaitis, G. CIGS thin-film solar module processing: Case of high-speed laser scribing. Sci. Rep. 2017, 7, 1-9. [CrossRef]

21. Schroder, D.K. Semiconductor Material and Device Characterization, 3rd ed.; Wiley-IEEE Press: Hoboken, NJ, USA, 2015; ISBN 978-0-471-73906-7.

22. Palma, A.L.; Matteocci, F.; Agresti, A.; Pescetelli, S.; Calabrò, E.; Vesce, L.; Christiansen, S.; Schmidt, M.; Di Carlo, A. Laser-Patterning Engineering for Perovskite Solar Modules with 95\% Aperture Ratio. IEEE J. Photovolt. 2017, 7, 1674-1680. [CrossRef]

23. Turan, B. Scribe Width Optimization of Absorber Laser Ablation for Thin-film Silicon Solar Modules. J. Laser Micro/Nanoeng. 2013, 8, 234-243. [CrossRef]

24. Rakocevic, L.; Gehlhaar, R.; Merckx, T.; Qiu, W.; Paetzold, U.W.; Fledderus, H.; Poortmans, J. Interconnection Optimization for Highly Efficient Perovskite Modules. IEEE J. Photovolt. 2017, 7, 404-408. [CrossRef]

25. Gupta, Y.; Liers, H.; Woods, S.; Young, S.; DeBlasio, R.; Mrig, L. Optimization of a-Si Solar Cell Current Collection. In Proceedings of the Conference Record of the IEEE Photovoltaic Specialists Conference, 16th edition. San Diego, CA, USA, 27-30 September 1982; pp. 1092-1101.

26. Di Girolamo, D.; Phung, N.; Jošt, M.; Al-Ashouri, A.; Chistiakova, G.; Li, J.; Márquez, J.A.J.A.; Unold, T.; Korte, L.; Albrecht, S.; et al. From Bulk to Surface: Sodium Treatment Reduces Recombination at the Nickel Oxide/Perovskite Interface. Adv. Mater. Interfaces 2019, 6, 1900789. [CrossRef]

27. Kosasih, F.U.; Cacovich, S.; Divitini, G.; Ducati, C. Nanometric Chemical Analysis of Beam-sensitive Materials: A Case Study of STEM-EDX on Perovskite Solar Cells. Small Methods 2020, 2000835. [CrossRef]

28. Di Girolamo, D.; Phung, N.; Kosasih, F.U.; Di Giacomo, F.; Matteocci, F.; Smith, J.A.; Flatken, M.A.; Köbler, H.; Turren Cruz, S.H.; Mattoni, A.; et al. Ion Migration-Induced Amorphization and Phase Segregation as a Degradation Mechanism in Planar Perovskite Solar Cells. Adv. Energy Mater. 2020, 10, 2000310. [CrossRef]

29. Kosasih, F.U.; Rakocevic, L.; Aernouts, T.; Poortmans, J.; Ducati, C. Electron Microscopy Characterization of P3 Lines and Laser Scribing-Induced Perovskite Decomposition in Perovskite Solar Modules. ACS Appl. Mater. Interfaces 2019, 11, 45646-45655. [CrossRef]

30. Matteocci, F.; Vesce, L.; Kosasih, F.U.; Castriotta, L.A.; Cacovich, S.; Palma, A.L.; Divitini, G.; Ducati, C.; Di Carlo, A. Fabrication and Morphological Characterization of High-Efficiency Blade-Coated Perovskite Solar Modules. ACS Appl. Mater. Interfaces 2019, 11, 25195-25204. [CrossRef]

31. Giordano, F.; Petrolati, E.; Brown, T.M.; Reale, A.; Di Carlo, A. Series-Connection Designs for Dye Solar Cell Modules. IEEE Trans. Electron. Devices 2011, 58, 2759-2764. [CrossRef]

32. Xu, X.; Shi, J.; Wu, H.; Yang, Y.; Xiao, J.; Luo, Y.; Li, D.; Meng, Q. The influence of different mask aperture on the open-circuit voltage measurement of perovskite solar cells. J. Renew. Sustain. Energy 2015, 7, 043104. [CrossRef]

33. Wang, J.; Zardetto, V.; Datta, K.; Zhang, D.; Wienk, M.M.; Janssen, R.A.J. 16.8\% Monolithic all-perovskite triple-junction solar cells via a universal two-step solution process. Nat. Commun. 2020, 11, 5254. [CrossRef]

Publisher's Note: MDPI stays neutral with regard to jurisdictional claims in published maps and institutional affiliations.

(C) 2020 by the authors. Licensee MDPI, Basel, Switzerland. This article is an open access article distributed under the terms and conditions of the Creative Commons Attribution (CC BY) license (http://creativecommons.org/licenses/by/4.0/). 